Issue 2/2017

\title{
PERFORMANCE MANAGEMENT AT THE ORGANIZATIONAL LEVEL
}

\author{
Nicola TERRACCIANO ${ }^{1}$ \\ ${ }^{1}$ Frederico II University of Naples, Via Candole, 1 Santi Cosma e Damiano \\ 04020, Italy, Email: nicolaterracciano@yahoo.it
}

\begin{abstract}
Performance management is ,a strategic and integrated approach to delivering sustained success to organizations, by improving the performance of the people who are working in them, and by developing the capabilities of teams and individual contributions" [Armstrong M. and Baron D, 1998]. At the same time, it is a systematic approach of the human resource management, in general, and of the performance assessment, in particular, using goals, performance, appreciation and feedback as a means of motivating the employees to understand and to fully exploit their creative potential to achieve the organizational goals.
\end{abstract}

Keywords: performance; appraisal; skills; assessors; evaluated.

JEL Classification: $\mathrm{D}_{23}, \mathrm{M}_{51}, \mathrm{M}_{54}$

\section{Introduction}

In an organization, the concept of "Performance" has become one of the most commonly used. Employers look for the top performers, and employees want to be stimulated to be better at the place where they work. To achieve the performance, some companies believe that it is enough to fix and then communicate to employees a set of goals, while others use specific tools to manage this indicator. Nowadays, more and more companies are seeking to institutionalize as much as possible and appeal to what specialists call performance management.

"The traditional level in which the performance management is used in organizations is the individual level, with a focus on monitoring the performance of employees in an organizational context. Internationally, the trend is for an integrated approach to the performance management at all organizational levels." [Adrian Brudan, 2011] 


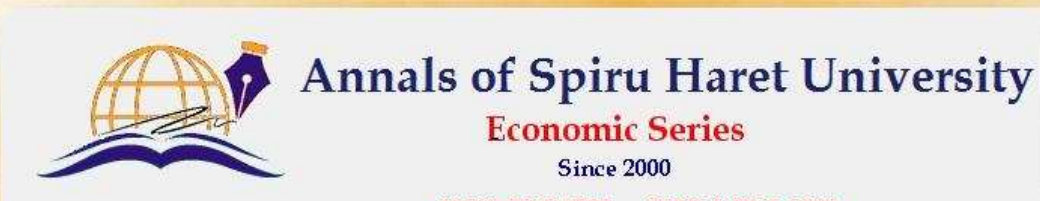

ISSN: 2393-1795 ISSN-L:2068-6900

Issue 2/2017

Performance management in Romania is in an early stage of development, although the principles that underlie the performance management are simple and logical in the organizational culture of any company. In recent years, interest in the performance management in Romania increased.

The performance management is top-down and involves all the layers that make up the organization - from management to departments and employees taken separately. Thus, in order to achieve the proposed goal, the entire management process involves constant evaluation, realignment and continuous improvement activities. The organization practices a certain performance management, but what makes the difference is how accurately the performance management practices are implemented and applied. Among the most common dangers to a company that does not make performance management is the emergence of a semi-chaos state, due to the inability to align strategies to objectives and then to performance indicators. It can also easily install employee dissatisfaction that affects the same indicators.

\section{Organizational strategic options}

Performance management is strategic in the sense that it concerns more general issues faced by an organization in order to be able to function effectively in the environment where there is the general direction which it wishes to adopt in order to achieve its longer-term objectives. Performance management needs to be integrated into the complex management process of the organization and to be correlated with other key processes such as organization strategy and employee development.

Integrated character implies:

- Vertical integration - is done with the organization's economic strategy. At team and individual levels there are goals that support the achievement of the organizational goals. They take the form of coordinated goals in a downward direction, from the organizational level, at the function level to the level of the team and individual employee. Strict alignment of these objectives is essential and, above all, agreeing on objectives that must be reached through open dialogue between managers and employees.

- Horizontal integration - involves aligning strategy of the performance management with other human resources strategies, particularly on the organizational development, evaluation, remuneration, to achieve a consistent approach of the management and development of the organization's staff. 


\section{Annals of Spiru Haret University \\ Economic Series \\ Since 2000 \\ ISSN: 2393-1795 \\ ISSN-L:2068-6900}

Issue 2/2017

- Integration with organizational and individual needs. A model of unanimously accepted performance management does not currently exist, but many authors talk about the existence of a performance management cycle. One such model is presented below and contains five elements [Panaite N. and collaborators, 2011]:

1) setting the goals;

2) measurement the performance;

3) obtaining the feedback on the measurement;

4) rewarding in the direct relationship with the results;

5) modifying and completing the objectives and activities.

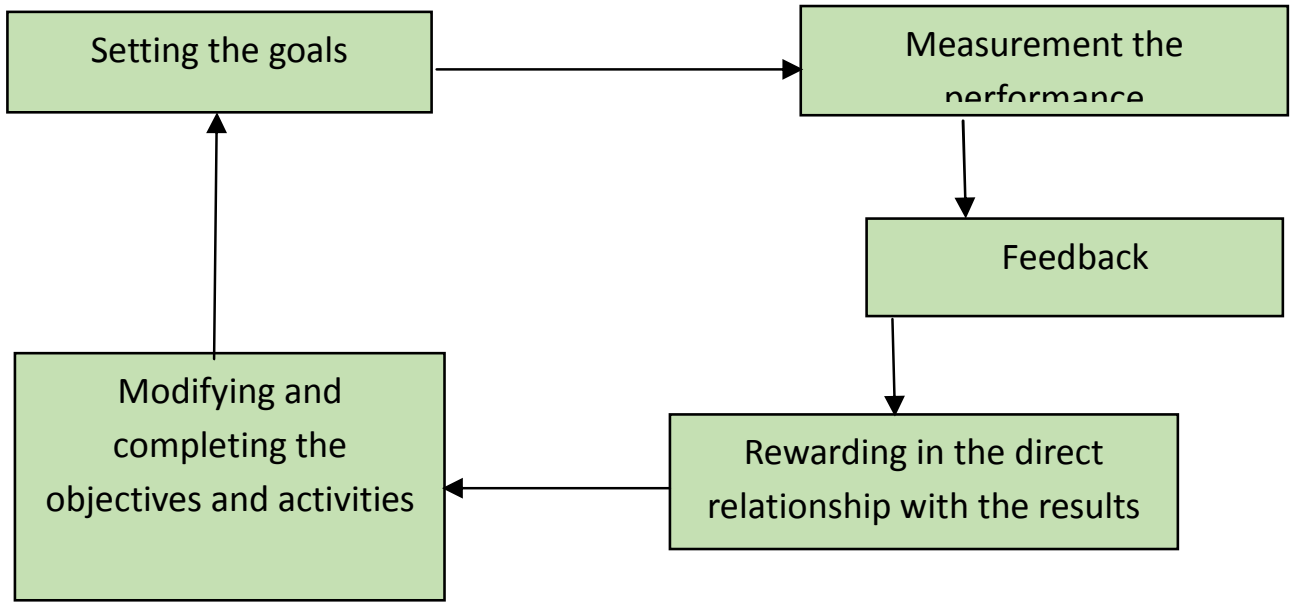

Figure no. 1. The performance management cycle

Source: Panaite N. and collaborators, work cited 2011, pp. 81

This cycle presents a way in which the process should be conducted by the organizations wishing to adopt a strategic perspective of human resource management. The level at which such a system can operate depends on how the organization wishes to apply this model. The model does not specify the level at which these elements are applied: at the individual level, at the team level, in the departments or strategic units or at the level of the whole organization, but leaves it to the management of the organization to choose it. 
Issue 2/2017

Performance management must be seen as an integral part of the ongoing process of managing the organization's activity, targeting:

- achieving a sustained improvement of the performance;

- continuous development of skills and overall competence;

- importance of organizational learning.

The performance continuous assessment process should be conducted by reference to the agreed objectives and performance standards and according to the developed and improved work plans.

The five key elements of the performance management are [Armstrong M., 2003]:

1) measuring - evaluating the results in relation to agreed the objectives and standards; tasks;

2) feedback - providing employees with information about how to perform

3)positive reinforcement - emphasizing what has been done well, constructively criticizing of the negative aspects, that is, in a manner that indicates how to improve;

4) exchange of opinions - total, free and sincere about what has been achieved and what needs to be done to achieve more (reaching agreement on what needs to be done for the future);

5)agreeing the action plans to be implemented by the employees, autonomously or with the support of their managers.

Performance management is a continuous and flexible process that focuses primarily on planning and improving the future performance rather than retrospectively assessing of the past performance, providing the basis for systematic and frequent dialogue between managers and employees, their performance and development needs.

In Romania, there are various assessment systems of the staff [Pitariu H., 2006] in organizations as it is aware of the beneficial effect of this activity on the employees' productivity, recognizing its necessity for increasing the competitiveness level of the organizations. In practice, the specialists are confronted with various requirements, imposed by law, criteria of the predetermined performance. Objectivity is another issue faced by organizations in the assessment process, many times evaluators misunderstanding the content of performance standards and compelling to evaluate superficially. 


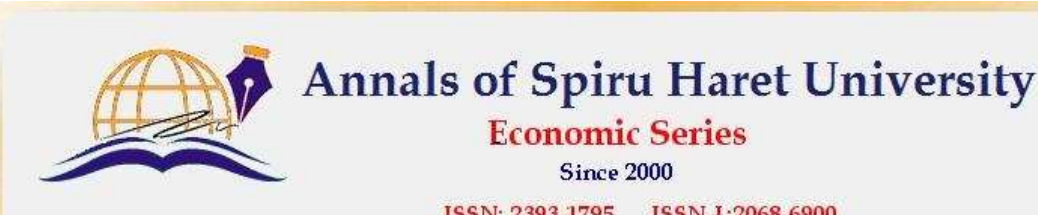

ISSN: 2393-1795 ISSN-I.2068-6900

Issue $2 / 2017$

\section{Measuring the human resource performance}

This process refers to the measurement of the quantifiable job results: number of pieces, labour productivity, number of clients, number of customer complaints, etc.

For dimensions that cannot be measured, it is necessary to achieve some estimates, by means of which it becomes possible to quantify them. These estimates are generally performed by the performance appraisal method. The tool used for this purpose is the employee performance appraisal sheet, which can take many forms.

Some job results will be measurable while others are unquantifiable. Only measuring the results (produced products, number of sold products, etc.) does not provide sufficient data and may even lead to less motivation and satisfaction of employees. Both the work results and employee behaviours should be evaluated.

The chosen criteria must take into account:

- Organizational objectives: performance appraisal should be organized in accordance with available information and its use. If the productivity data is of interest to a section or a team, and the evaluation should be done at the same level. Along with the actual work tasks, it will include elements promoted by the organization in human resources policies: creativity, professional development, managerial qualities, poly-qualification, flexibility, etc.

- Position: in choosing the job tasks to be assessed, account will be taken of those on which the employee has control. In addition to work tasks, the performance appraisal will take into account the responsibilities and authority of employees.

- Employee needs: facilitating the communication between management and employees. Employees are generally interested in promoting the opportunities. They may sometimes want to talk about their post or their team, and the inability to address these problems can lead to frustration, dissatisfaction, absenteeism, and even resignation.

The most important thing is using of multiple criteria to capture as many facets of performance as possible on a particular position. These criteria will be assigned weightings according to the importance and contribution to success on the job. These weights will help to aggregate the obtained score by each criterion in part in a global score. 
Issue 2/2017

Criteria for performance appraisal must be of high degree of objectivity, which gives equity to evaluation and increases the employee confidence in the process, especially as they play a decisive role in tiebreaker in the event of dismissal.

Criteria for performance appraisal appreciate the following:

1. Soft skills: are more difficult to assess because they are not attested by diplomas but result from the employee's behaviour. The assessment starts from the premise that there are effective and ineffective behaviours and that they have been identified for each job or type of job. Behaviours are considered effective or ineffective depending on the results they produce them (desirable or indescribable). Examples: teamwork, quality of work, communication skills, involvement, initiative, ethics, client orientation, flexibility, adaptability, innovation, efficiency, empathy, etc.

2. Technical skills: are specific to a particular business sector and can be acquired through learning; they are easier to evaluate than soft skills and their possession is confirmed through the diplomas/qualifications obtained. Examples: knowledge of a foreign language, project management, grammar, writing, computer skills, etc.

3. Personality traits: The first graphical scales evaluated the employees based on the personality traits that were supposed to be related to the work being done. One inconvenient of the exclusive using of this type of criteria is that personality traits are rather difficult to define and can be interpreted differently. Examples: conscientiousness, extraversion, emotional stability, opening to new, agreeableness, etc.

4. The personal development plan aims at developing the employee by improving the specific skills to his/her current position and his/her preparing for new responsibilities and positions. It may constitute an assessment criterion when pursuing the original objectives set out therein. On the basis of the assessment, the development plan can be established for the next period.

5. Individual performance goals determine the level of performance which the employee must achieve. Their correct setting is very important in achieving the expected results. It is recommended to reflect the objectives of the departments. In order for the departmental objectives to reflect the company's objectives, their formulation is based on the mission, vision and strategic objectives of the company. Only after identifying the departmental objectives can be set the individual performance targets, depending on the job description. In order to allow an effective evaluation, it is recommended that the objectives to be SMART: Specific, Measurable, Affordable (achievable), Relevant, framed over Time. Example: Sales 


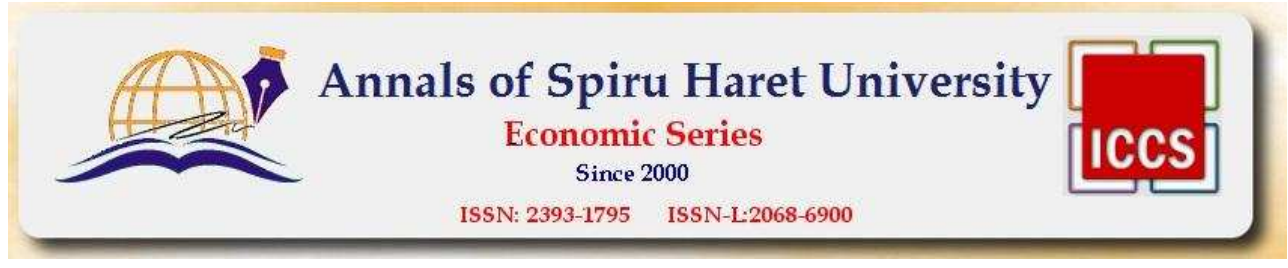

Issue $2 / 2017$

growth by 5\% over the last quarter of the previous year, within 6 months of signing the evaluation sheet.

Companies can set different weights for the evaluation criteria, depending on what they are tracking through this process.

Assessors

People who perform the performance appraisal [UMCS Group, 2012] play a very important role in the entire evaluation process because they can significantly influence the obtained results. In order to obtain the most accurate results, the assessor must have information on: the valuation procedure, the company's objectives, the responsibilities of each employee's position, the performance of the employees as well as the clear standards on which performance will be noted.

In choosing the assessor, three factors must be taken into account:

- the opportunity to observe the activity of the evaluated person;

- the ability to translate observations into scores;

- motivation to provide performance information: motivation may be influenced by the assessors' confidence in the evaluation process, by the request to justify their assessments, and the evaluator's knowledge of how to resolve conflicts generated by less satisfactory evaluations. Increased motivation can be achieved by providing training for assessors addressing important issues in evaluating and communicating the results, and including the performance appraisal in the job duties as an important part of the assessors' work.

Assessors differ greatly from each other as a result of individual differences of a psychological and professional demographic nature.

The characteristics of the evaluated will influence, consciously or unconsciously, his assessment, having an impact on the assessor's perceptions and impressions. The characteristics of the evaluated person can also be grouped into three categories: demographic factors, psychological factors and professional factors.

The choice of the assessor may vary depending on the position occupied by the evaluated person and the type of the company. Assessors can be:

- hierarchical superiors of each employee;

- the employee himself (when the evaluation process also contains a selfassessment component);

- subordinates (when managers are evaluated);

- colleagues or external assessors. 


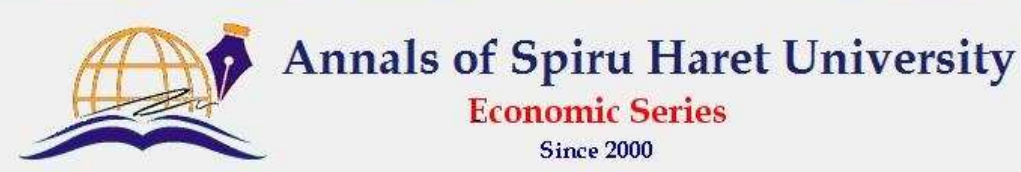

Issue 2/2017

Depending on the particularities of each evaluation process, several assessors may be involved.

\section{The objectives of the assessors}

The assessor, which aims to estimate the resource status of an organization, including the human resource, will start by analyzing the organizational and human structures, because the staff and the enterprise market are the most important elements that determine the value of a business.

The organizational structure analysis starts from the organizational chart. Based on this, hierarchical and functional relationships, hierarchical levels and weights are determined. It is analyzed the current status of the functions in relation to age. It is determined whether the successions are well prepared and whether there is a risk of ,gaps" in the coming years.

Starting from the organizational chart, we can see the rational way in which the management functions in the enterprise are distributed and the way in which the information circulates from one echelon to another, both vertically and horizontally. The assessor needs to know if the instructions and information easily move from top to bottom (hierarchically) and if there is communication between services.

The long-term action plan should show how administrative organization and decision-making are taken, as well as the existence of a control mechanism.

The evaluator has to verify whether the decisions are substantiated, budgeting, and are transmitted, implemented, controlled and quantified for deviations beside the budget provisions.

Business management needs to be evaluated from a performance point of view. If the company has a performance appraisal system, it can do so based on it. The assessor should observe the links of the leadership towards a group or a majority shareholder, the style of management (collegially, authoritatively, centrally, decentralized), the age of the management members, their formation, seniority in society, decision areas and the limits of commitment and hierarchical control, their relations with certain economic and social environments (clients, suppliers, employees, banks), their image inside and outside the firm.

The assessor will then pursue the provisions of the collective labour agreement, the extent to which it is respected the laws and the decisions in force, and whether it is actually respected.

The stability index determines the loyalty of the staff and looks at the possibilities for replacement in the event of departure, and in case of retirement if there is a succession. The assessor checks the policy of recycling of all existing 26 


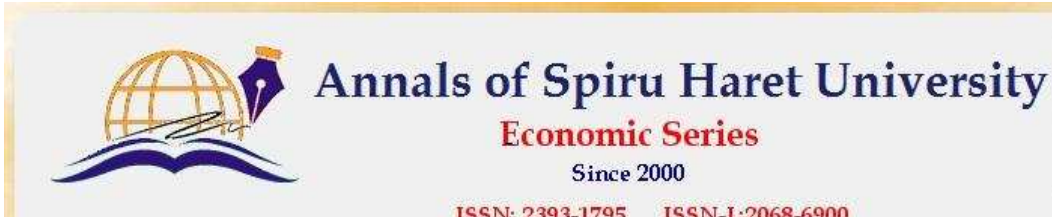

ISSN: 2393-1795 ISSN-I.2068-6900

Issue 2/2017

staff in all echelons, allowing not only good performance on the busy position but also the possibility of promoting in other positions.

It also seeks to ensure that recruitment and employment are followed by a period of prior orientation/training, the existence of a staff surplus or inadequate staff, labour productivity, normalization of the work (safety margins, flexibility offered by different types of contracts, coverage the positions), employee reputation, employee skills (specific: technical and general knowledge: customer relations, employees, managerial spirit, leadership). The assessor will observe the local, national and international reputation of the human resources managers and the management, in general.

In general, they can be considered strengths: the high weight of young staff, rational organizational structure, collegial leadership, good training of the company's staff, open atmosphere and lack of conflicts and litigation between leadership and trade union.

The weaknesses in human resources area and their management can generally be considered: insufficient staff training, opposition to the new and innovation, the unbalanced organizational chart, dictatorial leadership style, lack of interest in the company assets, numerous and unresolved litigations, inability for solving the problems. The human resources management assessment will cover the two components: evaluation of its efficiency and equity.

\section{Conclusions}

"Every human activity aims at a specific purpose, and way to achieve that goal or misses it shows us how well or how badly that activity is taken place" [Laurenția Avram, 2010].

Performance appraisal is an important component of the performance management within the organization and it is considered an integral part of human resource management in the current context of its development.

The evaluation is carried out by the direct heads, as the team coordinators, who evaluate their subordinates on the basis of general and specific criteria for each position. Most of the time, the evaluation takes place under the coordination of the human resources manager.

The organization applies a well-structured system for evaluating the performance based on its own methodology, designed to meet the needs of the organization.

It is realised an evaluation of both managers and executives, both categories being evaluated on the basis of well-defined competence criteria; the process is carried out within the assessment centres (Assessment Centres). 


\section{Issue 2/2017}

An essential part of the evaluation process is the interview that allows for more effective communication between the assessor and the evaluated, while ensuring a rapid feedback.

Another important aspect is the communication of the objectives to be achieved at the beginning of the year, especially of the individual objectives, and the establishment of a continuous evaluation of their achievement.

The communication of the performance appraisal results is essential considering that these bonuses are received according to these results and the change of salaries is determined in the following year. Employees benefit from feedback on their activity, telling themselves what they do well and how well they can, and how they can improve and are encouraged to reach their goals.

As a result of the evaluation process, there are established the development programs of the professional skills through specific trainings (training courses by category of staff, applying mentoring and coaching programs).

Review the performance has the role of adapting the objectives and the performance criteria over the time after formulating some possibilities for improvement.

\section{References}

1. Armstrong, M., Human Resources Management - Practice Manual (Bucharest, CODECS, 2003).

2. Armstrong, M. \& Baron, A., Relating Competencies to Pay: The UK Experience, Compensation and Benefits Review (Nay-June, 1998).

3. Avram, Laurentia, The business from a macro-social perspective (Bucharest, Annals of Spiru Haret University, vol. 10, No 2, 2010).

4. Cole, G. A., Organizational Behavior (London, Ashford Colour Press, 1998).

5. Hudson, H., The Perfect Appraisal (London, Century Business, 1992).

6. Hunt, N., Conducting staff appraisals - How to set up a review system that will ensure fair and effective appraisals and improve individual performance and organizational results (Wiltshire Trowbridge Cromwell press, 2005).

7. Manolescu, A.; Lefter, V.; Deaconu, A., Human Resources Management (Bucharest, Economică, 2007).

8. UMCS Group - Professional Performance Appraisal, April 2016, www.ucmsgroup.ro

9. Resourcefulness Report 2015 - facts and figures

10. CNVM Report 2014, https://www.omvpetrom.com

11. Corporate Governance Statute of OMV Petrom on March 14, 2015, https://www.omvpetrom.com/ 